Res Publica. Revista de Historia de las Ideas Políticas

ISSN-e: 1989-6115

https://dx.doi.org/10.5209/rpub.63611

\title{
Acumulación y subjetivación en el neoliberalismo: Estado, workfare y discurso gerencial
}

\author{
Sergio Vega Jiménez*
}

Recibido: 07 de marzo de 2019 / Aceptado: 10 de junio de 2019

Resumen. En el siguiente artículo se lleva a cabo un balance de las principales líneas de la crítica al neoliberalismo, concediendo especial importancia a las transformaciones del Estado, al workfare como nuevo modo de regulación y de prestación social, y a los discursos gerenciales, también conocidos como new management o nuevas teorías de gestión empresarial, que se han delineado en las últimas décadas como el discurso gerencial que apuntala los cambios en la organización del trabajo al servicio de la maximización del beneficio. Como se expondrá, por el carácter híbrido y heterogéneo del neoliberalismo, se hace necesaria la conjunción de la crítica marxista que aborda este fenómeno como nuevo régimen de acumulación y las críticas de raigambre foucaultiana que lo afrontan como modo de subjetivación o forma de racionalidad.

Palabras clave: Estado; workfare; discursos gerenciales; neoliberalismo; ciudadanía.

\section{[en] Acumulation and Subjectivation in Neoliberalism: State, Workfare and Management}

\begin{abstract}
The following article takes stock of the main lines of criticism of neoliberalism, giving special importance to the transformations of the State, to work as a new mode of regulation and social benefit, and to managerial discourses, also known as new management or new theories of business management, which has been delineated in recent practices as the discourse that is underpinned by changes in the organization of work at the service of maximization of production. As it will be explained, on account of the hybrid and heterogeneous character of neoliberalism, it is necessary a conjunction of Marxist criticism of this phenomenon as a regime of accumulation and the foucauldian criticism of it as a mode of subjectivation or rationality form.
\end{abstract}

Keywords: State; Workfare; Management; Neoliberalism; Citizenship.

Sumario: 1. Introducción. 2. Los procesos de neoliberalización y el papel del Estado. 3. Hacia un workfare-State. 4. ¿Después del welfare? Los discursos gerenciales y la ciudadanía de baja intensidad. 5. Conclusiones.

Cómo citar: Vega Jiménez, S. (2019). Acumulación y subjetivación en el neoliberalismo: Estado, workfare y discurso gerencial, en Res Publica 22.2, 533-550.

\footnotetext{
" Universidad de Barcelona vegasergio.94@gmail.com
} 


\section{Introducción}

En este artículo se pretende indagar en el neoliberalismo como forma de racionalidad y tecnología de poder que subyace a nuevas formas de subjetivación y de relación con todo ámbito. La exigencia que se nos plantea tras los logros alcanzados por los debates más recientes es una lectura estratégica del neoliberalismo y de los procesos de neoliberalización, desafiando las topologías verticales, pero sin descuidar la enorme demanda de Estado que el neoliberalismo realmente existente ha puesto en juego a cada paso. Lo que se delinea como una crisis del trabajo es teorizado principalmente desde la forma concreta en que el Estado neoliberal ha articulado un nuevo modo de regulación (el workfare), estableciendo sus conexiones con las mutaciones en las formas de la ciudadanía, lo social y la comprensión de la acción colectiva, para estudiar la relación entre el modelo de empresario de sí y un cierto fenómeno de desdemocratización ${ }^{1}$. Como se ha estudiado desde otras corrientes, las nuevas formas de organización del trabajo quedan íntimamente vinculadas a los objetivos de una productividad incrementada y una desmovilización política sustentada por las distintas estrategias del management ${ }^{2}$.

El neoliberalismo, como objeto de estudio, comparece como movilización ubicua de relaciones competitivas, de lógica y de gobernanza desjuridificadora. Siendo un concepto que ha alcanzado una hipertrofia inigualable, bien sea para decretar durante un tiempo su muerte o para insistir en su mutable supervivencia, los diagnósticos del proceso de neoliberalización han ido ganando en sutileza. Las disputas conceptuales entre las que se mueve la teoría crítica del neoliberalismo plantean la necesidad de una articulación de la crítica marxiana del capitalismo con las herramientas foucaultianas. Se trataría, por tanto, de teorizar simultáneamente las formas de acumulación y el análisis crítico de las nuevas formas de subjetivación. Desde este punto de vista, el neoliberalismo será analizado por su implementación procesual y diferencial, considerada desde un abordaje multiescalar, que no rinda los análisis macro ni las disquisiciones sobre los resortes subjetivos. Pero, si se tiene en cuenta el peligro de una concepción inflacionaria de éste, así como de un modelo adelgazado del concepto, para que no se convierta en la ganzúa que abre todas las puertas tiene que ser aplicado a una serie de concreciones prácticas (institucionales y subjetivas), donde se muestra como herramienta útil para analizar mutaciones (profundamente adjetivadas por éste) en los planos del Estado, el trabajo y la subjetividad.

A nivel metodológico, mantenemos una posición inspirada en la escuela de la regulación y solidaria del cruce entre las herramientas marxistas y foucaultianas: la intersección entre norma, territorio y fuerza de trabajo como claves para una interpretación de la acumulación y las relaciones de poder desde su dimensión espacio-

\footnotetext{
Cf. W. Brown, El pueblo sin atributos, Barcelona, Malpaso, 2016.

El vocablo management refiere a ese conjunto de técnicas, teorías y discursos de gestión empresarial que existen desde finales del siglo XIX pero adquieren un cariz entusiasta y motivador a partir de los años 60 . Comparten la aspiración racional de la gestión científica del trabajo de figuras como Taylor o Ford, pero se mezclan con las estrategias de marketing, los libros de autoayuda y los manuales de las materias de gestión impartidas en las escuelas de negocios. En el seno de estas mismas escuelas, ha surgido una corriente crítica conocida como los Critical Mangement Studies (CMS), localizada principalmente en las universidades británicas y confrontada en España por la sociología crítica de autores como Luis Enrique Alonso y Carlos Jesús Fernández Rodríguez. Cf. C.J. Fernández Rodríguez (ed.) Vigilar y organizar. Una introducción a los Critical Management Studies, Madrid, Siglo XXI, 2007.
} 
temporal. En línea con esta premisa, nos preguntaremos por el papel del Estado en el neoliberalismo realmente existente, el tipo de normatividad articulada por el discurso managerial, y, finalmente, por la posible coexistencia, en un modo de gobierno que se presume garante de amplias cuotas de libertad, de mecanismos disciplinarios y estrategias posdisciplinarias. Se tratará, desde esta perspectiva dual, de pensar la acumulación y los modos de regulación desde la intersección entre territorio, norma (conjunción de ley, discurso, tramas de interlocución, narrativas públicas, culturas políticas y laborales...) y fuerza de trabajo.

\section{Los procesos de neoliberalización y el papel del Estado}

Tras la crisis de 2008 el capitalismo neoliberal pudo resurgir, intensificado e hipervitaminado, con la inestimable ayuda de los Estados. A medida que la retórica neoliberal ha ido permeando todas las prácticas sociales y justificando las drásticas medidas de austeridad, los diagnósticos críticos han afilado sus armas para dar cuenta del fenómeno del neoliberalismo, bien sea como racionalidad política o bien como proyecto estatal de reforma incesante, siempre bajo parámetros de mercado. A menudo, la dificultad que se plantea es si acaso se trata de un concepto omniabarcante o si, por el contrario, se torna necesario cuando el concepto adquiere un carácter deflacionario y nos permite adjetivar una serie de transformaciones sociales en curso. Independientemente de la matriz teórica escogida para analizar los procesos de neoliberalización, es ineludible "la enorme demanda de Estado que exigen la ingeniería social neoliberal y los procesos de acumulación capitalista", así como su papel en la "contención de la protesta social y fortalecimiento de la división internacional del trabajo" . En ese sentido, el Estado es una de las principales palancas de tales cambios y uno de los elementos cuya práctica es adjetivada por el neoliberalismo, entendido en su dimensión procesual.

Los estudios sobre la transformación del Estado neoliberal han subrayado su segmentación y funcionalización al servicio del mercado y de los procesos de cambio global multiescalar. Los Estados habrían virado de un modelo clientelista y corporativista a un nuevo tipo de estatalidad que reconfigura y subordina las agencias públicas al servicio del mercado y de la creación de un orden competitivo en todos los ámbitos sociales. Es importante subrayar que este proceso de neoliberalización de distintas instancias (públicas y privadas) no consiste en una mera retracción del Estado o un desmantelamiento total de lo público, sino que, muy especialmente, tendría lugar a través de una disposición de toda instancia bajo criterios competitivos ${ }^{4}$.

A nivel metodológico destacan tres aspectos de la mayor importancia para entender la especificidad del neoliberalismo como proceso transformador. En primer lugar, el hiato existente entre las prescripciones de la teoría neoliberal y las formas adquiridas por los neoliberalismos realmente existentes, para lo cual es preciso partir de la distin-

P. López, "Sigue cierta algarabía. Michel Foucault, el neoliberalismo y nosotros", en R. Castro y A. Salinas (eds.), La actualidad de Michel Foucault, Madrid, Escolar y Mayo, 2016, pp. 231-254, aquí p. 247.

4 De esta manera, los abordajes geográficos y sociológicos sobre el neoliberalismo atienden a una necesidad de complementar los estudios de la gubernamentalidad aportando contenido institucional y consideraciones sobre la espacialidad que a menudo no comparecen en las críticas del neoliberalismo como "racionalidad política" global. Cf. C. Laval, P. Dardot, La nueva razón del mundo, Barcelona, Gedisa, 2012. 
ción de Harvey entre Estado neoliberal en la teoría y Estado neoliberal en la práctica 5 . En segundo lugar, el enfoque relacional que priman autores como Bob Jessop y Loic Wacquant a la hora de estudiar el Estado podría ser insertado, a pesar de las disputas teóricas, en un intento de complementariedad entre la escuela de la regulación y la teoría del campo burocrático desarrollada por Bourdieu, en la medida en que ambos enfoques atienden a realidades extraeconómicas y extraestatales para explicar tanto la organización del trabajo como las políticas públicas en su dimensión conflictual. El enfoque regulacionista, tal y como es formulado por Jessop, consigue explicar los procesos de naturalización de un espacio económico dado. Ahí confluyen tramas socioculturales e institucionales amplias, que desbordan lo meramente estatal y movilizan tramas de interlocución transversales a distintos ámbitos sociales, configurando narrativas públicas que acompañan epocalmente a una forma de regulación social concreta ${ }^{6}$. En el caso de la racionalidad neoliberal y su apropiación de las agencias públicas, las narrativas han estado presas de conceptos imperativos como "reducción del déficit", "recuperación económica", "restricción presupuestaria" y "crecimiento"7. Además, como señala Hilgers, estas prescripciones se amparan en un discurso que se arroga objetividad, presentándose como un "capitalismo científico". Todo ello redunda en una despolitización de debates cruciales como la financiación de las políticas asistenciales en favor de un vocabulario técnico y una cultura de expertos.

El otro aspecto central de la transformación del Estado, y que resulta de la mayor importancia para plantear su relación con las crisis del empleo ha sido la tendencia a un cambio de las coberturas del welfarismo por un programa workfarista, ligado, como demuestra Wacquant, a una expansión punitiva del Estado neoliberal. No se trata solamente de una excepcionalidad local sino de una tendencia que inevitablemente comienzan a adoptar otros países para gobernar la inseguridad provocada por una degradación de las condiciones de trabajo y un aumento de la marginalidad urbana. La heterogeneidad de formas en que el neoliberalismo se implementa exige un análisis multifocal, entendiendo el Estado, la penalidad y las políticas públicas como espacios de conflicto interno cuyo análisis no podría reducirse ni a la óptica de la lucha de clases ni a las inercias de una ubicua racionalidad política ${ }^{9}$.

No obstante, seguiremos la precaución de varios autores a la hora de plantear una lectura estratégica del neoliberalismo, como tecnología de gobierno compleja y como proceso multiescalar ${ }^{10}$. Quizá, más que dar una definición exhaustiva del concepto de neoliberalismo, lo que resulta teóricamente productivo es indagar en los problemas y

D. Harvey, Breve historia del neoliberalismo, Madrid, Akal, 2005, pp. 77-80.

6 B. Jessop, “¿Narrando el futuro de la economía nacional y el Estado nacional? Puntos a considerar acerca del replanteo de la regulación y la re-invención de la gobernanza", en Documentos y aportes en administración pública y gestión estatal, 7, pp. 8-44, aquí, p. 32.

$7 \quad$ J. Peck, "Explaining (with) neoliberalism", Territory, Politics, Governance, 1(2), 2013, pp. 132-157, aquí p. 86.

8 M. Hilgers, "The Historicity of the Neoliberal State", en Social Anthropology/Anthropologie Sociale, 20 (1), 2012, pp. 80-94, aquí p.82.

$9 \quad$ Más allá de las discrepancias específicas en el debate sostenido por Jessop, Hilgers, Peck y Wacquant en la revista Social Anthropology hay un acuerdo sobre la necesidad de abordar el estudio del Estado de manera relacional, por contraposición a explicaciones funcionalistas e instrumentales. De tal manera que entienden la cristalización de una institucionalidad y una correlación de fuerzas como fruto de conflictos entre distintas posiciones y diferentes modos de hacer, entre fracciones de clase y también al interior de la administración. A este respecto, Jessop identifica en el Estado una selectividad estratégica, que responde a una comprensión del Estado como relación social.

10 V. Gago, La razón neoliberal, Madrid, Traficantes de sueños, 2015, p. 31; J. Peck, op. cit., pp. 149 ss. 
las contradicciones sociales que podemos explicar con éste. Si persisten los debates sobre su uso, es porque sigue teniendo un poder explicativo, siempre y cuando no sustituya debidas explicaciones concretas. Por ello, apuntamos a la necesidad de plantear la relación entre los cambios en la estatalidad y las transformaciones del trabajo, lo cual se traduce en un examen de las nuevas formas de prestación social y los discursos de autorresponsabilización asociados al nuevo régimen de trabajo obligatorio (workfare). Tal es el rendimiento del análisis multiescalar: la teoría no tiene que decidir, de manera excluyente, entre una etnografía localista y una teoría de la totalidad ${ }^{11}$. Se trata, por el contrario, de atender al neoliberalismo como racionalidad que permea distintos ámbitos y atraviesa variados paisajes institucionales, adquiriendo formas híbridas ${ }^{12}$. La propuesta de lectura estratégica de Foucault y del neoliberalismo, en la que insiste Verónica Gago, arroja luz sobre la necesidad de desafiar las topologías políticas verticales y atender a la particular espacialidad neoliberal, a la manera en que se relaciona la configuración del territorio con las formas flexibles de organización del trabajo. Dos categorías cruciales (territorio y fuerza de trabajo) a las que referimos en los primeros compases del texto y que, como afirma la autora en su estudio sobre la feria ilegal de La Salada, son "coordenadas fundamentales para explicar la heterogeneidad del espacio global" fruto de "la explosión de las geografías estatal nacionales" y "la implosión que fuerza a determinados territorios y actores a inesperadas conexiones que facilitan los procesos de producción y explotación del trabajo"13.

Una de las claves que se derivan del debate sobre el Estado neoliberal es que el neoliberalismo sólo puede existir imbricándose con otras formas sociales ${ }^{14}$. No se puede establecer una explicación monocausal, ya que toda causalidad que intentemos atribuir a un proceso complejo requiere considerar específicamente y comparativamente coyunturas y contextos espaciales (locales, regionales, estatales...). Pero, como bien advierte Peck, cuando hablamos de este carácter abigarrado de las tecnologías neoliberales de gobierno, la retórica del ensamblaje, "la evocación de su carácter «híbrido» no es un mero tic posestructuralista sino un indicador de las inevitables formas impuras en las que las tendencias neoliberalizadoras se encuentran" [traducción propia] ${ }^{15}$. Toda vez que la neoliberalización es un proceso incompleto, que debe reanudarse a cada paso, conviviendo de forma contradictoria con otras tendencias, tradiciones políticas y culturales, y diseños institucionales no estrictamente emparentados con la ideología neoliberal. El neoliberalismo necesita parasitar diseños institucionales ya dados, de ahí que resulte del mayor interés el análisis comparado de las variaciones locales de la estatalidad neoliberal. La cuestión es ver cómo, en la práctica, "las hegemonías de mercado están siendo continuamente reconfiguradas a través de un desarrollo espacial desigual", así como "reconocer las vías por las que todas las formaciones locales se constituyen conjuntamente, no sólo con «otros» distantes sino con redes formativas («technocratic expertise» and «policy norms») y relaciones diferencialmente escaladas (de naturaleza fiscal o geopolítica, por ejemplo)" [traducción propia $]^{16}$.

\footnotetext{
V. Gago, La razón neoliberal, op. cit., p. 31.

J. Peck, "Explaining (with) neoliberalism", op. cit., pp. 143-144.

V. Gago, La razón neoliberal, op. cit., p. 101.

J. Peck, N. Theodore, "Reanimating neoliberalism: process geographies of neoliberalisation", en Social Anthropology/Anthropologie Sociale, 2012, 20 (2), pp. 177-185, aquí p. 183.

15 J. Peck, "Explaining (with) neoliberalism", op. cit., p. 140.

16 Ibidem, p. 140.
} 
La clave consistiría en rastrear la composición global de las fuerzas locales y, del mismo modo, la condensación local de las fuerzas globales. A la hora de analizar esa espacialidad desigual en las economías de la deuda, conviene apreciar que la deuda es la expresión de una específica relación de poder, en la que, además, toda entidad, local o estatal, compite con otras. Abordar la espacialidad neoliberal y su carácter desigual nos exige hacer referencia a la llamada financiarización y al tipo de arreglo espacial que ha acompañado a la construcción de las economías de la deuda. El concepto estrella de Harvey no es sólo una manera de explicar cómo el capital se fija al territorio, es también una manera de traer a colación la dimensión temporal de toda configuración espacial y su inserción en cadenas globales de valorización, por las cuales todo paisaje industrial es susceptible de ser deslocalizado para externalizar las consecuencias de la sobreacumulación. De la misma forma, el capital financiero puede introducirse en otros nichos de mercado con la connivencia de las élites urbanas o regionales, espacios marginales o secundarios respecto a los grandes referentes de las cadenas de valor en el fordismo. Esa producción de espacio al servicio de la valorización, se asienta sobre configuraciones espaciales previas y apunta a racionalizar un paisaje urbano a la medida del patrón de acumulación subsiguiente, hasta el punto de producir también una "división espacial del consumo" que permita asegurar la ventaja competitiva ${ }^{17}$.

Aunque David Harvey circunscribe su análisis del neoliberalismo a un aparente proyecto de reconstitución del poder de clase, que restaure tasas de beneficio anteriormente embridadas en los marcos del fordismo-keynesianismo mediante un pacto entre capital y trabajo, el relanzamiento del proceso de valorización mediante los distintos proyectos de neoliberalización se ha caracterizado por una intensa mercantilización del espacio y de la fuerza de trabajo Se esté de acuerdo o no con las conclusiones políticas del estudio de Harvey, la tendencia ineludible ha sido la aparición de nuevas estrategias de generación de beneficio que se han apoyado en las plataformas provistas por los estados. La intensa mercantilización del espacio y de la fuerza de trabajo es solidaria de la forma en que los Estados neoliberales entienden los mercados laborales: hostilidad a toda forma de solidaridad social que entorpezca la acumulación de capital; consecuente antisindicalismo; flexibilidad como consigna que, si bien beneficia en algunos empleos a los trabajadores, genera "asimetrías de poder y de información"; y control de la movilidad de la fuerza de trabajo (especialmente en las fronteras $)^{18}$.

En torno a esa estatalidad disciplinante se ha ido agrupando una miríada de actores, expertos, empresas e instituciones de distinto cuño, valiéndose de redes de contactos y prácticas a menudo negligentes, que Harvey denomina empresarialismo urbano, y que se perfila como una dinámica clave a la hora de canalizar las relaciones socioeconómicas en las ciudades posfordistas y de conducir a la transformación "desde un régimen de acumulación de capital fordista-keynesiano a un «régimen de

17 D. Harvey, Espacios del capital, Madrid, Akal, 2011, p. 377. Si una de las claves del capitalismo de posguerra era excluir de los criterios de mercado una serie de bienes fundamentales como la vivienda, la superación del estancamiento de los 70 se llevará a cabo por medio de la colonización de esos espacios previamente vedados a la lógica mercantil, siendo el espacio y, por consiguiente, las políticas urbanas y de vivienda, uno de los principales nichos de mercado a la hora de aumentar la tasa de ganancia. Se perfila, así, como una explotación intensiva del espacio y de las rentas del monopolio. Cf. A. Garrido, "Desembridado y posfordismo. Notas sobre la subjetividad neoliberal", en Astrolabio, 22, pp. 36-48.

18 D. Harvey, Breve historia del neoliberalismo, Madrid, Akal, 2005, p. 82. 
acumulación flexible»" ${ }^{\prime 19}$. No obstante, como ya se ha advertido, la neoliberalización no es un proceso que tenga lugar en el Estado y se disperse unívocamente hacia abajo. Como forma de racionalidad, es susceptible de ser apropiada al margen de imposiciones canalizadas por la política de Estado. En ese sentido, al empresarialismo urbano que Harvey examinaba, podríamos contraponer el ejemplo contemporáneo de la empresarialidad popular. El caso de estudio de La Salada, la mayor feria ilegal del mundo, tomada por Verónica Gago como síntoma de la permeabilidad del neoliberalismo, constituye otro polo de agregación de formas de empresa, trabajo y consumo que conjugan elementos populares y marginalidad urbana con elementos de la racionalidad neoliberal. La socióloga argentina muestra cómo se conforman conglomerados de negocios que permiten el relanzamiento de la acumulación y del proceso de valorización bajo estrictos parámetros de competitividad interna y externa. Conllevan altas dosis de auto-explotación combinadas con una democratización del consumo. Ahí, el taller textil clandestino explota un triple diferencial: salarial (explotación), de estatuto legal (semi-servidumbre) y de riqueza comunitaria (capital comunitario). Por las dosis de auto-explotación y por la simultánea puesta en juego de una autonomía con respecto a las reglas del empleo formal, la autora habla de una fundamental ambivalencia, por tratarse de "una red productiva que articula momentos comunitarios y de explotación brutal, protagonizada por sujetos migrantes, trabajadores, microempresarios" ${ }^{\text {"20 }}$, que es permitida desde ciertos estratos del Estado por adscribirse a la lógica del emprendimiento pero condenada desde otros sectores, por las vías de la moralización y la judicialización. Las nuevas formas de empresarialidad urbana, en su versión tecnocrática o en su variante popular, configuran una concreción político-institucional de los patrones de acumulación basada en generar beneficios en los circuitos secundarios de la cadena de valor, sobre una implantación territorial determinada, y con un recurso masivo al crédito, donde la logística juega un papel esencial como medio de creación de plusvalor ${ }^{21}$.

Las distintas formas de implementación que el neoliberalismo ha tenido desde sus comienzos (castigos ejemplarizantes, ataque a las culturas laborales y sindicales...) permite desbordar su estudio de la órbita del fordismo atlántico ${ }^{22}$. El paisaje contemporáneo arraiga en la espacialización desigual que tuvo lugar en los primeros compases de la neoliberalizaición. Hoy podríamos distinguir entre distintas formas de espacialidad que desbordan el marco del Estado nación y constituyen constelaciones posnacionales, con capacidad de imposición de norma en detrimento de las soberanías clásicas. Para estudiar la relación entre neoliberalismo, Estado y trabajo, nos interesa sobre todo atender a la relación de esta espacialidad con las nuevas formas de organización del trabajo y de prestación pública. Esto nos llevará a ver el

\footnotetext{
D. Harvey, La condición de la posmodernidad, Buenos Aires, Amorrortu, 2012, p. 370.

V. Gago, op. cit., pp. 37 y 135.

21 La importancia de la logística para la creación de plusvalor en el capitalismo contemporáneo ha sido subrayada por autores como Sergio Bologna. Pero más allá de las estandarizaciones de medida y volumen de carga, de las tácticas de externalización y de la racionalización de la Supply Chain Management, la articulación de distintas escalas en el comercio internacional se delinea como una heterogeneidad espacial cruzada con una heterogeneidad temporal, que algunos autores denominan "acumulación diferencial”. Cf. S. Mezzadra, "Extraction, Logistics, Finance”, en Radical Philosophy 178, 2013, pp. 8-18, aquí p. 12.

22 De hecho, fueron numerosos países africanos la punta de lanza de las políticas de ajuste estructural y de los préstamos condicionados. En la década de los 80, más de 244 préstamos del FMI y del Banco Mundial a 38 gobiernos africanos. Cf. M. Hilgers, 2012, "The Historicity of the Neoliberal State", op. cit., p. 83.
} 
proceso desdemocratizador en el ocaso de la ciudadanía laboral y la relación de los desarrollos geográficos desiguales ${ }^{23}$ con las asimetrías de poder en las economías de la deuda. Para ello, resulta crucial mostrar que la generalización de la forma-empresa en todos los ámbitos, acorde al programa neoliberal, ha derivado en una competencia inter-territorial e interestatal, primando siempre formas de decisión no democrática y los poderes ejecutivos por encima de los tiempos lentos de la deliberación pública. Bajo estos parámetros, la gobernanza prima siempre el lenguaje de la gestión y se vale de una razón jurídica a su medida. El concepto de gobernanza es intercambiable por el de gestión en la mayoría de usos, anunciando una "fusión importante de las prácticas políticas con las de los negocios"24. Bajo esta norma se priorizan los incentivos y se eluden las mediaciones institucionales del Estado del bienestar, alumbrando un modelo de gestión de marcado corte urbano que ha sido denominado fast policy por teóricos como Jamie Peck, basado en la competencia interterritorial. Son modos de gobernanza blanda, orientados a proyectos a corto plazo $^{25}$, amparados bajo un discurso modernizador y creativo, y que está enteramente dirigido a construir ciudad-marca, condición sine qua non de toda ciudad que se quiera competitiva.

Una de las condiciones para la modernización urbana y el fomento de la competitividad acelerada era un flujo constante de crédito (a los Estados y a las ciudades). Algo sostenible en las décadas de destrucción creativa de los Estados del bienestar, pero que produce cada vez más tensiones. La crisis de 2008 y el subsiguiente incremento de las deudas soberanas han supuesto un aumento del poder de los acreedores; un poder tal que implica capacidad de diseño de las políticas públicas y de la asignación de recursos, una re-orientación de las políticas hacia formas de colaboración público-privada, que no implican la destrucción de lo público, sino una sutil refuncionalización bajo criterios de competencia. Ante la evidente relación de chantaje que tiene lugar entre acreedores y deudores cabe introducir un matiz: la asimetría de poder en las economías de la deuda redunda en un diferencial de poder de los sujetos y de los Estados, y también en una inclusión diferencial en el juego de la competencia (con sesgos de clase, género y raza). Maurizio Lazzarato ha señalado esa aplicación diferencial mostrando la deuda como una relación de poder, al mismo tiempo que produce formas de subjetivación lastradas por la culpa y la moralización del sujeto deudor, de manera que el proceso de financiarización de las economías ha ido a la par de la reorganización del trabajo y de la constitución de un incesante trabajo sobre sí mismo, abarcando así "la producción económica y la producción de subjetividad" 26 . El sistema financiero, apoyado en la palanca del Estado neoliberal, se constituye como un mecanismo de explotación y disciplinamiento, una específica relación de poder que incide sobre los sujetos, las políticas y el tiempo. La relación entre acreedores y deudores adquiere un poder altamente constrictivo sobre las subjetividades y la financiación de las políticas públicas. Más allá del modelo de conducción de conductas, en la medida en que hipoteca a las generaciones presentes y futuras, se configura como una política del tiempo, como un modo de objetivación del tiempo futuro y de las posibilidades de acción, ampliando la explotación de la subjetividad

\footnotetext{
D. Harvey, Espacios del capital, op. cit., pp. 95-103.

W. Brown, op. cit., p. 164.

J. Peck, Constructions of Neoliberal Reason, Oxford, Oxford University Press, 2010, p. 218.

M. Lazzarato, La fábrica del hombre endeudado, Buenos Aires, Amorrortu, 2013, p. 13.
} 
extensiva e intensivamente ${ }^{27}$. Las economías de la deuda funcionan siempre sobre una asimetría de fuerzas, exigen una distribución desigual del poder y del espacio para generar la necesidad de una relación crediticia, al tiempo que proveen el marco de constitución de las mercancías. Ahora la fuerza de trabajo, o capital humano, debe esforzarse por mantener su solvencia, dando lugar a un "creciente proceso de individualización que apunta a neutralizar las lógicas colectivas" 28 .

En líneas generales, la mayoría de críticos del neoliberalismo coinciden en que el proceso de neoliberalización ha consistido en un rediseño de las agencias públicas, una segmentación y funcionalización del Estado al servicio de los imperativos de mercado, y un desarrollo geográfico desigual, con variantes locales y distintas formas de resistencia ${ }^{29}$. Agudamente, Jamie Peck califica de formaciones discrepantes a las cristalizaciones locales de estos procesos. De esta manera, la neoliberalización sería siempre una tarea incompleta, que nunca agota las prescripciones de su proyecto, y se ve obligada siempre a medirse con sus resistencias, cristalizando en formas híbridas y declinaciones locales a las cuales, no obstante, subyace un patrón común.

En lo que estarían de acuerdo todos los autores, a excepción de la reconstrucción algo más lineal de Wacquant, es en la heterogeneidad de la historia de los procesos de neoliberalización, en el sentido de una simultaneidad o coexistencia de lineamientos institucionales y políticos de distinto cuño, donde las formas nuevas no sustituyen absolutamente los modos de regulación anteriores, sino que se hibridan dando lugar a conjuntos funcionales a las exigencias de mercado de una región dada (el posfordismo atlántico, la Unión Europea, el sudeste asiático...). Esta heterogeneidad impide toda reconstrucción lineal del neoliberalismo, y sin embargo los patrones comunes a las distintas declinaciones locales de la neoliberalización nos impelen a analizar esa ratio subyacente. Ante tal heterogeneidad de lo social, como mínimo se puede mantener la precaución metodológica de Jessop, no reducir nuestra explicación del Estado neoliberal al funcionalismo ni al estructuralismo, sino realizar un balance de la estatalidad y sus transformaciones desde la selectividad estratégica, pensando cómo se articulan territorio y fuerza de trabajo. El modo de regulación que se anuncia abandera la flexibilización de los mercados laborales y el patrón de acumulación vendría caracterizado por la especialización flexible, relegando a la exportación de materias primas a unas economías, y a la especialización en actividades de alto valor añadido a las economías más desarrolladas ${ }^{30}$.

\section{Hacia un workfare-State}

Una de las consecuencias de la destrucción creativa de los mercados vendría a ser que los Estados neoliberales tienen que enfrentarse cada vez a mayores cuotas de inseguridad social y, puesto que el trabajo asalariado indefinido no parece una expe-

27 Ibidem, pp. 51-53, 60 .

28 Ibidem, p. 118.

29 J. Peck, op. cit., p. 180; B. Jessop, "Putting neoliberalism in its time and place: a response to the debate", en Social Anthropology/Anthropologie Sociale, 20 (1), pp. 65-74, aquí p. 73.

30 Cf. L.E. Alonso, C.J. Fernández, Poder y sacrificio. Los nuevos discursos de la empresa, Madrid, Siglo XXI, 2018 . 
riencia generalizable a toda la población, el Estado tiene que comportarse diferencialmente en función del segmento poblacional con el que se trata. Las sutilezas de esta operación han sido recogidas en los estudios de Loïc Wacquant sobre penalidad y workfare, apuntando al mismo tiempo al inmenso poder de producción simbólica del Estado. En su lectura del neoliberalismo, el Estado intentaría imponer la forma-mercado a la ciudadanía a través de una orientación de las políticas públicas hacia un régimen de trabajo obligatorio y mediante un endurecimiento de la penalidad hacia los estratos más bajos, con un marcado sesgo etnorracial ${ }^{31}$. Esta aplicación de un workfare restrictivo termina produciendo una gradación de la ciudadanía, haciendo uso constante de un discurso responsabilizador ${ }^{32}$.

La implementación de las políticas neoliberales ha tenido que medirse siempre con sus resistencias, con los conflictos despertados por el desgarro de los vínculos y las solideces institucionales del welfarismo en Europa, y de lo comunitario-agrario en el sur global. Este proceso de neoliberalización de todo ámbito social exige expandir los mecanismos de mercado y el modelo de la competencia. Como forma de gubernamentalidad contemporánea, se sustancia en una racionalidad política que permea toda práctica social y en las formas que tienen los sujetos de conducirse en su trabajo, en sus relaciones interpersonales y con las instituciones. En esa línea, compartimos la tesis de Wacquant que presenta al neoliberalismo como una articulación de Estado, mercado y ciudadanía, mediante la cual se intenta imponer a la ciudadanía las formas del mercado en relación con el trabajo, la penalidad y la vida personal, movilizando un discurso de autorresponsabilización. Los mecanismos estatales que ahí se ponen en juego implican un cambio hacia un modelo disciplinante de prestaciones combinado con un prisonfare expansivo, cuya relación con los nuevos pobres es de contención punitiva. Pero, sobre todo, el fortalecimiento del ala penal sería un proceso funcional a la constitución del Estado neoliberal, mediante el cual se regula la excrecencia de las fracciones inseguras del proletariado posindustrial y lo que fue un Estado habilitante en Occidente, termina siendo un "Estado deshabilitante para los que están en la parte más baja"33. Esta penalización de la pobreza divide a la ciudadanía en clases, pero no sólo en términos socioeconómicos. Lo que tiene lugar, más concretamente, es una gradación de la ciudadanía y de los derechos, respecto de la cual, Wacquant recomienda virar de una delgada concepción económica, a una concepción sociológica fuerte, "centrada en un Estado que especifica una maquinaria institucional involucrada en el establecimiento de un dominio de mercado y su impacto operativo en la membresía social efectiva" 34 , produciendo ciudadanos de segunda. Aunque entienda el neoliberalismo como un proyecto orquestado desde arriba, su concepción más matizada del funcionamiento del Estado y del campo burocrático permite entender la estratificación social que está teniendo lugar con la ayuda del Estado neoliberal, así como también muestra la trampa que subyace al problema de la inseguridad social, como promesa de resolución de dos grandes problemas inherentes a la mer-

31 Aumento de las penas por delitos menores, aumento desmesurado de la población reclusa o prohibición de acceso con antecedentes penales a la mayoría de trabajos.

32 L. Wacquant, Castigar a los pobres: El gobierno neoliberal de la inseguridad social, Barcelona, Gedisa, 2009, p. 72 .

33 Ibidem, p. 436.

34 L. Wacquant, "Three steps to a historical anthropology of actually existing neoliberalism", en Social Anthropology/Anthropologie Sociale, 20 (1), pp. 66-79, aquí p. 71. 
cantilización: 1) "frena las dislocaciones crecientes causadas por la normalización de la inseguridad social en la base de las clases y la estructura urbana", y 2) "restaura la autoridad de la élite gobernante reafirmando «la ley y el orden» justo cuando esta autoridad se ve socavada por los flujos acelerados de dinero, capital, signos y personas, a través de las fronteras nacionales, y por la restricción de la acción estatal por parte de cuerpos supranacionales y del capital financiero"35.

Es en este punto donde Wacquant consigue apresar las claves de la producción de inseguridad, la subsiguiente demanda de seguridad y los resortes del discurso securitario, que tiene el efecto de restaurar la apariencia de un Estado fuerte, garante del orden y la ley, en un momento de declive de las soberanías frente a los poderes económicos. Si el autor acuña el concepto de pornografía penal ${ }^{36}$ para hablar del exceso de publicidad en torno al delito, que ayudaría a construir el relato justificador de la penalidad expansiva, el precario equilibrio que los Estados mantienen en torno a la soberanía, la migración y las presiones del capital internacional nos permite calificar de pornografía securitaria a la incidencia obsesiva en la seguridad nacional y la migración. El análisis de Wacquant acerca de las políticas asistenciales y del campo burocrático en las sociedades neoliberales apunta a mostrar que la penalidad está adoptando un rol instrumental: permite un disciplinamiento de clase y cumple con la "misión comunicativa de proyectar seguridad y soberanía"37.

Ante esta relación entre ciudadanía, trabajo y seguridad cabe preguntarse si la contención punitiva y el workfare disciplinario estarían inaugurando un nuevo modo de regulación tal que explota siempre un diferencial de poder, que no se aplica uniformemente sobre toda la población, sino que diversifica sus estrategias de intervención en función de los recursos y los segmentos sociales a los que afecta (workfare disciplinario para las clases precarizadas, gubernamentalidad creativa para las clases medias). En vista de cómo el Estado redibuja los límites de la ciudadanía a través de políticas mercantilizadoras y penales, volcadas al modelo competitivo, los diagnósticos de este tipo nos permiten plantear un contrapunto tanto a las lecturas marxistas y foucaultianas, como a las posiciones encuadradas en la óptica de la subalternidad. No obstante, la mínima caracterización de la coerción y vertiente penal del Estado neoliberal, para apresar el entramado institucional del Estado neoliberal precisamos de la teorización que ofrece Wacquant, señalando una operación doble: la imposición de un workfare restrictivo en condiciones precarias, y un prisonfare expansivo. Este giro punitivo de las sociedades y los gobiernos neoliberales mostraría una incapacidad de éstas para disciplinar y constataría la imposibilidad de integrar a todos los sectores sociales en el juego de la competencia. La atención a estas dinámicas de penalización y exclusión permite vislumbrar la íntima relación entre las crisis socioeconómicas y las reorganizaciones del sistema productivo. Tanto el desempleo como la demanda de seguridad vienen a mostrar que "el vínculo entre «workfare» $\mathrm{y}$ «prisonfare» cumple funciones interrelacionadas que responden a necesidades de

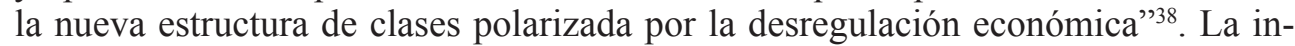
seguridad social es fruto, por tanto, de la erosión del trabajo estable y de las viejas solidaridades de clase y de cultura que se sostenían en un marco regional y nacional.

Ibidem, p. 76.

L. Wacquant, Castigar a los pobres, op. cit., pp. 303-327.

L. Wacquant, "Three steps...", op. cit., p. 76.

L. Wacquant, Castigar a los pobres, op. cit., p. 19. 
Frente a esa desarticulación, la utilidad del aparato penal en la era poskeynesiana es la "disciplina del nuevo trabajo fragmentado" 39 .

En definitiva, el estudio de las transformaciones del trabajo, del neoliberalismo y del Estado, no debe caer ni en una perspectiva estatofóbica ni en un estadocentrismo. La convergencia de enfoques simbólicos, genealógicos y sociohistóricos permite captar las precondiciones para el surgimiento del poder estatal y su relación con las luchas sociales. Evitando tanto una idea reduccionista del Estado neoliberal podemos entender la articulación de éste con nuevas formas de regulación de los mercados laborales sin un proyecto fijo; se trataría de una selectividad estratégica según la cual la política estatal va respondiendo a las coyunturas. En todo caso, la tendencia a un workfare disciplinario responde más a las exigencias que plantea la crisis del trabajo que a un oscuro proyecto de las élites neoliberales.

\section{4. ¿Después del welfare? Los discursos gerenciales y la ciudadanía de baja intensidad}

Si leemos los informes de la patronal francesa tras los conflictos del 68 o el informe de la Trilateral, lo que más se acusa es una crisis de gobernabilidad, una simultánea crisis de autoridad y del beneficio capitalista. El informe de la Trilateral señalaba un exceso de democracia y la necesidad de excluir a una serie de actores, por incómodos y obstaculizadores de la gestión pública; dictaminaba que lo necesario para una democracia efectiva era "la apatía y la no-participación de parte de ciertos individuos y grupos" $" 40$. En la misma década, comienzan a popularizarse una serie de discursos gerenciales, en ese momento más cercanos a la autoayuda de bolsillo que a una práctica de largo recorrido científico. ¿A qué aspiraba la retórica afectiva que emergía con fuerza, apelando al cambio, la innovación y la creatividad?

Si tiene sentido preguntarse por el concepto de empresario de sí es porque éste ha terminado cristalizando en el modelo de sujeto que ansía no sólo la teoría neoliberal, sino también toda una serie de prácticas que pueden ser adjetivadas por el concepto de neoliberalismo, las cuales conducen, en última instancia, a producir adaptación a las dinámicas de mercado competitivo -generando adhesión entusiasta y haciendo pie en las críticas de época a las rigidices del Estado-providencia ${ }^{41}$. Aunque desde varios frentes de las ciencias sociales se han estudiado sistemáticamente los comportamientos efectivos del empresario de sí, es necesario advertir, como venimos mostrando, que la heterogeneidad de las formas de autoconducción en el contexto de la gubernamentalidad neoliberal precisa de una atención a la aplicación desigual de esa normatividad (por ejemplo, en función de variables como la clase o el género). Aquí optamos por atender a los discursos gerenciales en la medida en que permean las prácticas tanto de las instituciones públicas como de las entidades privadas.

$\mathrm{Si}$, desde la escuela de la regulación, subrayábamos la necesidad de articular territorio, fuerza de trabajo y producción de norma, se podría estudiar el discurso gerencial como una especificación de la racionalidad neoliberal con poder de produc-

Ibidem, p. 36.

40 Citado en A. Santamaría, En los límites de lo posible: política, cultura y capitalismo afectivo, Madrid, Akal, 2018, p. 56.

41 Cf. L.E. Alonso y C.J. Rodríguez, op. cit.; A. Santamaría, op. cit. 
ción de norma y formas de castigo de toda desviación que no debemos eludir ${ }^{42}$. Los discursos gerenciales dan un soporte al management en la empresa y a la ya mencionada gobernanza urbana, sustanciándose en estrategias de comparación y extracción de ventaja competitiva, como el benchmarking y las llamadas mejores prácticas ${ }^{43}$. Desde la filosofía nos corresponde aprehender las líneas motrices del discurso que da soporte a la ficción del empresario de sí. El objetivo es destapar la arbitrariedad y la violencia que subyacen a la naturalización de estos discursos. Nos preguntamos por las condiciones de posibilidad, por el fondo de emergencia de una racionalidad y la dosis de violencia que conlleva la arbitrariedad de una norma social que rompe con los vínculos previos. Se trata de pensar al mismo tiempo las condiciones de aceptabilidad del management.

Toda variante histórica del entramado de socialización capitalista necesita desplegar la fuerza de trabajo sobre el territorio en un marco estable, asegurando su reproducción, bajo una institucionalidad y una producción de norma reguladora. La norma que acompaña al imperativo de competitividad es un modelo de subjetivación no estable, lanzado al cambio y a la innovación constantes. En consecuencia, la falta de un modelo de ciudadanía, criterios de legitimación y consenso en el neoliberalismo, en una economía acelerada sin las previsiones contracíclicas del keynesianismo y la pacificación de las relaciones laborales que llevaban asociada ${ }^{44}$, se suple con la alternativa de una aceptación entusiasta del nuevo marco sociolaboral mediante un incesante activismo cultural. Es una intervención en todos los ámbitos, que aspira a reducir la distancia entre trabajo y vida personal, movilizando una retórica de cambio, creatividad e innovación social. La clave es reducir el coste del tránsito entre trabajo y tiempo libre, o incluso hacerlos coincidir, empresarializando a cada instante la relación social. De esta manera queda asegurada la productividad, impidiendo la desconexión con el trabajo, que es considerada un error gravísimo por toda la literatura managerial, "en la medida en que eso genera mayor ansiedad, así que la tesis es situar el trabajo en el centro de la vida privada y, de este modo, la transición vida-trabajo generará menor estrés" ${ }^{45}$. Por su coste e improductividad, la "infelicidad" habrá de ser eliminada tanto como, o más que, la conflictividad laboral.

El objetivo es tornar todo malestar en adhesión entusiasta. Esta práctica se configura como un dispositivo afectivo blando, un tipo de gubernamentalidad creativa que tiene dos efectos, disminuir el potencial conflictivo de los afectos (en su vertiente reactiva) tornándolos adhesión al modelo de competitividad, y "generar ciudadanía de baja intensidad" ${ }^{46}$. La clave de esta política de lo sensible, a la que Santamaría denomina capitalismo afectivo, reside en la dinámica según la cual el capitalismo se apropia de la retórica cuestionadora para su propia revolución cultural. Y, como advertían Luc Boltanski y Ève Chiapello en su monumental estudio, disminuir "la

42 Comentando lo que supone una racionalidad política como orden de razón rectora que da forma a las prácticas políticas, a los sujetos y a los objetos (campos de aplicación), Wendy Brown se vale de la teorización de Foucault para destacar que todo discurso hace circular un tipo de verdad en la que también se cifra una categorización de la desviación. Por la misma razón, la racionalidad neoliberal no está exenta de distintas vías de castigo por incumplimiento de sus preceptos.

43 W. Brown, El pueblo sin atributos, op. cit, pp. 179-185.

44 Cf. J. Donzelot, La invención de lo social. Ensayo sobre la declinación de las pasiones politicas, Buenos Aires, Nueva visión, 2007, p. 127.

45 A. Santamaría, op. cit., p. 43.

46 Ibidem, p. 41. 
vigilancia sobre antiguos puntos de contestación"47 a partir de ciertas concesiones. La creatividad y la innovación social constituyen el marco de esta política de lo sensible, apuntando a minimizar los efectos anticompetitivos al interior de la empresa y fuera de ésta ${ }^{48}$. Este dispositivo inhibe los malestares producidos por la competitividad extrema y los canaliza en una dirección adecuada.

Si el neoliberalismo es algo, además de la ratio que subyace a la política de sociedad que sueña y aplica, es este particular modelo de sujeto que promueve, el empresario de sí, que, para hacer valer la diferencia en el mercado competitivo, tiene que valerse de los recursos afectivos y creativos aquí mencionados. Esta figura, basada en las teorías del capital humano, no está dada. Es, al igual que los mercados, una creación política. Y durante décadas ha necesitado de un impulso por parte de los discursos gerenciales, que han lubricado los cambios organizativos en el mundo laboral instalando el espíritu de empresa sobre cualquier otro tipo de óptica colectiva. El imperativo al que se somete todo capital humano es la lucha constante contra la propia depreciación. Al mismo tiempo, la retórica afectiva está enteramente orientada a la promoción de las propias energías, que no permitan decaer las pulsiones competitivas; como indica Pablo López, "cuando la preocupación subjetiva esencial es si se podrá resistir el trabajo, psíquica y físicamente"49, emerge todo un arsenal para engrasar las relaciones laborales. Creatividad, afectos, redes o inteligencia emocional: todos ellos son recursos movilizados para aumentar nuestra "energía", para reproducir la disposición afectiva necesaria a la hora de sostener ritmos endiablados de trabajo, o lidiar con la colonización de la vida privada por el trabajo.

La lucha contra la depreciación es una preocupación constante por el aumento de la empleabilidad. En condiciones de flexibilidad e inseguridad social, "la política social (...) ya no tiende tanto a ser una política de ciudadanía universal y nacional, cuanto que de focalización sobre grupos de riesgo -y de mantenimiento de esos grupos en una situación de cierta integración social mínima y funcional" 50 . No obstante, la cuestión es que el mantra de la empleabilidad permea por igual en empleos estables, perfiles profesionales y fracciones inseguras en el límite del trabajo precario. La empleabilidad es empuñada tanto por las políticas públicas como por la empresa privada. Incide sobre los grupos de riesgo a modo de contención en el trabajo precario y sobre los sectores más integrados, mediante política laborales vaciadas de toda dimensión redistributiva, imponiendo la competitividad individualizada a todos los sectores, haciendo "que las acciones estatales estén gobernadas por el pragmatismo, por la rectitud financiera, por el control milimétrico de los menguantes subsidios sociales, por la obligatoriedad de la búsqueda de empleo, por la incentivación del autoempleo o cualquier otra forma de «desafiliación» de la relación salarial estable"51.

Debemos tener en cuenta que tras el estancamiento del fordismo-keynesianismo en los 70, la retórica de la gestión empresarial incidía en la innovación social y el liderazgo, puesto que las crisis de rentabilidad exigen una transformación espaciotemporal de los mercados y "son las que marcan los cambios organizativos y del consiguiente discurso" $" 52$. Es un momento en el que este tipo de discursos son soste-

\footnotetext{
47 L. Boltanski y È. Chiapello, El nuevo espiritu del capitalismo, Madrid Akal, 2002, p. 75.

48 Cf. L.E. Alonso y C.J. Rodríguez, Poder y sacrificio, op. cit., pp. 54-55.

49 P. López, "La plasticidad forzada. Cuerpo y trabajo", en Daimon, 5, pp. 679-688, aquí p. 687.

50 L.E. Alonso y C.J. Rodríguez, Poder y sacrificio, op. cit., p. 94.

51 Ibidem, p. 95.

52 Ibidem, p. 43.
} 
nidos por quienes ostentan el poder en la empresa, directivos, ejecutivos y parcialmente cuadros medios. Sin embargo, la generalización de la flexibilidad laboral, el desempleo crónico y la incertidumbre de los mercados en las décadas posteriores, constituye la condición de posibilidad de una extensión del discurso gerencial a otros ámbitos, transformando de raíz los modelos de contratación y el trabajo que el sujeto lleva a cabo sobre sí mismo. Ahora, el mantra de "la empleabilidad implica el sometimiento de todo trabajador a instancias de examen continuo y a la exigencia de renovación permanente de las aptitudes" ${ }^{33}$.

Cuando intentamos aprehender el modelo de sujeto que esconde la racionalidad neoliberal, se trata no sólo de hallar exhaustivamente sus notas, sino de pensar también los modelos de sujeto, en concreto, de sujeto político, que habrían quedado cancelados - la ciudadanía laboral, la responsabilidad social, el compromiso, la afiliación sindical y política, el activismo y la protesta o la defensa de los derechos sociales. En la era fordista-keynesiana la relación entre mundo del trabajo y derechos sociales constituía una pacificación del conflicto entre capital y trabajo, convirtiéndose en la principal representación de lo social ${ }^{54}$. Funcionaba como un modo de regulación con los suficientes contrapesos para no condenar permanentemente a la inseguridad, socializando los riesgos mediante distintas formas de mutualización y bajo una concepción solidarista del Estado y del derecho. Así, la promoción de lo social apuntaba a "la reducción de los riesgos de todos y el simultáneo aumento de las oportunidades de cada uno" 55 . Ahí, la relación salarial era "la institución fundamental en la distribución y redistribución del poder social, lo que los discursos manageriales actuales ignoran hasta la desvergüenza" ${ }^{56}$. El tipo de institucionalización del vínculo social que la relación salarial ponía en juego perfilaba al individuo como ciudadano y sujeto de derechos, conteniendo las prerrogativas del derecho económico en límites no antagónicos a la socialización de los riesgos. Por el contrario, el cambio fundamental que tiene lugar en las sociedades neoliberales y en el modo de regulación propio del workfare es una sustitución de la retórica de los derechos por la jerga del deber y la responsabilidad. El beneficiario de ayudas, ya no lo es "por derecho" sino por "merecimiento", de manera que se promociona una "inclusión activa en el mercado laboral sobre la exclusión pasiva, ya que el workfare busca empujar a los pobres al mercado laboral, o sostenerlos en un estado persistentemente inestable cercano a éste" ${ }^{57}$ [traducción propia]. Se pasa del demandante de empleo al buscador activo de empleo, forzando una serie de modificaciones del comportamiento, mediante técnicas de auto-examen, vigilancia continua, y castigo por incumplimiento. El workfare pone en juego técnicas de seguimiento individual y rendición de cuentas, constituyendo un modo de regulación bajo el cual los derechos se han de merecer a cada paso; al no ostentarse incondicionalmente, el usuario de prestaciones sociales tiene que ser merecedor de éstas.

Si, como apunta Francisco Vázquez, la gubernamentalidad liberal del welfare transitaba de una noción reparadora a una noción de "bienestar total"

P. López, "La plasticidad forzada", op. cit., p. 685.

J. Donzelot, op. cit., p. 90 ss.

Ibidem, p. 102.

L.E. Alonso y C.J. Rodríguez, Poder y sacrificio, op. cit., p. 201.

57 J. Peck, "The rise of the workfare state", en Kurswechsel: Zeitschrift für gesellschafts-, wirtschafts- und umweltpolitische Alternativen, 3, pp. 75-87, aquí p. 78.

58 F. Vázquez "Del welfare al wellness: las tecnologías de bienestar y el gobierno de las subjetividades en el libe- 
workfare cambia no sólo el modelo de prestación sino la forma de subjetivación de la ciudadanía. El problema del workfare, como modo de regulación, es que moviliza una retórica culpabilizadora, donde la responsabilización, en su dimensión heterónoma, no equivale al acto de ser responsable. Al contrario, "la condición administrada de ser responsabilizado se aleja del dominio de la agencia, gobierna al sujeto mediante un requerimiento moral externo: a través de exigencias que emanan de otro lugar invisible" 59

Las estrategias de workfare contribuyen a la reproducción social de los trabajos precarios, aumentan la tasa de explotación, pero no aplacan el desempleo ${ }^{60}$. Si el Estado neoliberal también puede ser adjetivado como workfarista es por haber redimensionado las relaciones de competitividad, delineándose como un "Estado de competición" ${ }^{61}$, al calor de la cultura emprendedora, el consenso en torno a la autorresponsabilización y la imposibilidad de financiar un Estado de bienestar total.

El complemento de la recepción pasiva de prestaciones en el Estado de bienestar era una concepción activa de la ciudadanía, contra la cual también abren fuego los discursos gerenciales, constituyendo una episteme de mercado, neutralizadora de todo conflicto. El discurso gerencial se perfila explícitamente como una antipolítica que reemplaza las viejas solidaridades por la responsabilidad individual, siendo el mecanismo clave a la hora de apuntalar la adhesión a la dinámica competitiva y eliminando "cualquier pulsión desestabilizadora tendente al conflicto social" ${ }^{62}$. Las estrategias motivadoras del capitalismo afectivo corren paralelas a este proceso de desdemocratización, ligado a la pérdida de toda óptica de marcos de acción colectiva. La matriz interpretativa que la racionalidad neoliberal instaura sólo ve capitales en competencia. La pérdida del referente colectivo llega hasta el punto de considerar al ciudadano un consumidor en el mercado de las opciones y las ideas políticas, que compra con su voto - o con su dinero, en el caso de las campañas estadounidenses- lo que quisiera ver realizado en la política estatal ${ }^{63}$.

Ese hiato entre lo económico y lo político que la racionalidad neoliberal parece suprimir era lo social, presentado por algunos autores como un tercer elemento que sutura las tensiones entre dichos ámbitos ${ }^{64}$. Sutilmente, la racionalidad neoliberal tiende a acoger en su seno la racionalidad social y la racionalidad económica, previamente antagónicas, canalizándolas en la dirección de la dinámica competitiva, que conlleva individualización y fragilización de los vínculos, y la socialización más intensa bajo criterios de creatividad, innovación y diferencia. El reverso de esa fusión de las racionalidades social y económica constituye una inversión donde lo social no colma ninguna necesidad de vínculo sino una demanda de seguridad y protección

ralismo avanzado", 2018, I Encuentro Interdisciplinar sobre el Bienestar (Cádiz, 18-20 abril 2017). Texto de la intervención, s.n.

59 W. Brown, op. cit., pp. 177-178.

60 J. Peck, "The rise of the workfare state", op. cit., p. 11.

${ }^{61}$ Cf. B. Jessop, "The transition to postfordism and the schumpeterian workfare state", en Towards a Schumpeterian Workfare State? Preliminary Remarks on Post-Fordist Political Economy, Londres y Nueva York, Routledge, 1993, pp. 13-37.

62 A. Santamaría, En los límites de lo posible, op. cit., p. 175.

63 Incide en ello Wendy Brown al analizar el fallo del juez Kennedy en la sentencia por la limitación de las donaciones empresariales a las campañas políticas (Citizens United v. Federal Election Commission 558 U.S. 310 [2010]) En el texto, el juez prima la posesión de derechos sobre los efectos de las acciones, mostrando toda interferencia gubernamental como ilegítima, a menos que vaya dirigida a garantizar la libre competencia.

64 Cf. J. Donzelot, op. cit.; M. Lazzarato, op. cit., pp. 144-145. 
de derechos fuertes de propiedad, al tiempo que se apoya en discursos entusiastas y motivadores para maquillar la precarización de las condiciones laborales. Si el neoliberalismo tiene este carácter activista es por tener que reanudar a cada paso estrategias cohesionadoras para un modelo que supone el desgarro de todo vínculo social.

\section{Conclusiones}

Hemos perfilado la figura del empresario de sí o capital humano por la descripción previa de la política de sociedad, concretada en la arquitectura institucional que ha acompañado a los procesos de neoliberalización y el rediseño de los Estados. La particular utopía del neoliberalismo es generalizar el modelo de empresa a todos los ámbitos y relaciones sociales. El neoliberalismo impone una objetividad social basada en la competitividad, la reforma constante y la funcionalización de la política de Estado, sirviéndose de y promocionando activamente, mediante los discursos gerenciales, modos de subjetivación asociados al capital humano. De todo ello, la implicación política más directa es la desdemocratización y la producción de ciudadanía de baja intensidad, como proceso paralelo al ocaso de la ciudadanía laboral. Se podría deducir que esta indiferencia por la democracia es también indiferencia por la desigualdad, o por la estrecha relación entre libertad e igualdad. Una relación que la teoría neoliberal desdeña, por la sospecha sobre toda acción gubernamental que tenga efectivos anticompetitivos. En consecuencia, tiene lugar una elisión fundamental: el diferencial de poder que generan relaciones de competitividad extrema en un contexto de desigual acceso a los mercados y los recursos, obviado por los discursos justificadores de esta normatividad. En vista de tal disparidad, podríamos hablar de un neoliberalismo de dos velocidades, donde la polarización social y las desigualdades agravadas, junto a la individualización de riesgos que en el pasado eran socializados, son un prerrequisito de la sociedad competitiva.

Ese diferencial de poder nos lleva a constatar que la dominación no es homogénea. En ese neoliberalismo de dos velocidades los mandatos de competencia y de participación se asimilan diferencialmente, en función de las diferentes capas poblacionales, así como de la situación de los Estados, territorios y ciudades en las economías de la deuda. La heterogeneidad que pesa sobre la dinámica del capitalismo neoliberal nos compromete con una operación teórica: atender a la convivencia de formas disciplinarias y posdisciplinarias en la gubernamentalidad neoliberal. Si atendemos simultáneamente al carácter disciplinario del workfare y a los resortes afectivos de las tecnologías neoliberales, vemos que, como señala Francisco Vázquez, "no ha tenido lugar el fin de la disciplina", sino que "la disciplina recae sobre las capas poblacionales más pobres, intensificada bajo los parámetros del workfare", mientras que las tecnologías neoliberales, que incentivan más que castigan, recaen principalmente sobre clases medias y profesionales. Ahí, "la producción del bienestar, identificado con el gozo obtenido de la maximización de las capacidades y éxitos (...) es inseparable de la generación de un malestar alcanzando a todos los que se apartan de ese ideal normativo" ${ }^{\circ 5}$. La aplicación diferencial del workfare disciplinario y su convivencia con estrategias competitivas, despolitizadoras y generadoras de

65 F. Vázquez, op. cit., s.n. 
adhesión es consustancial a la crisis del trabajo, y constituye el mejor ejemplo para que la teoría no se decida entre disyunciones excluyentes (disciplina o biopolítica, guerra o gubernamentalidad...), toda vez que una sociedad estratificada y altamente diferenciada tiene que combinar mecanismos disciplinarios y estrategias posdisciplinarias para su reproducción.

El neoliberalismo se ha sustanciado, a través de sus distintas implementaciones, en dos modelos de praxis social: a nivel subjetivo, el individuo competitivo o empresario de sí, amparado por los discursos gerenciales, y en el ámbito de la política, el rediseño de las agencias públicas y privadas bajo parámetros competitivos. La inclusión de mayores ámbitos sociales en la lógica mercantil y la asunción de relaciones competitivas a distintas escalas (relaciones laborales, territoriales, interestatales...) corre paralela a la necesidad de subordinar las estrategias disciplinarias al aumento de la productividad.

En el neoliberalismo, Estado, trabajo y ciudadanía se articulan de una forma novedosa. Las fracciones sociales ya no integrables en el trabajo asalariado son sometidas a imperativos de competitividad y auto-responsabilización que constituyen un intenso disciplinamiento social. A este modo de regulación, denominado workfare, subyace una relación de contención punitiva con los excedentes del mercado laboral y una suspensión de cantidades cada vez mayores de trabajadores en los límites de la precariedad. Los procesos de neoliberalización, que se han servido del Estado como palanca de transformación, arraigan en una espacialidad híbrida y desigual. El diferencial de poder entre agentes y escalas es consustancial a la dinámica social a la que aspira el neoliberalismo en la teoría y en la práctica, de manera que sus tecnologías y estrategias no se aplican homogéneamente sobre toda la población. Como se ha visto, su aplicación diferencial arraiga en desigualdades previas y condiciones espaciotemporales diferenciadas, pero esa heterogeneidad deja también un resquicio para la resistencia. 